\title{
Comments on Paper by B. Isacks, J. Oliver, and L. R. Sykes, 'Seismology and the New Global Tectonics'1
}

\author{
C. F. RICHTHR \\ Seismological Laboratory, California Institute of Technology \\ Pasadena, Califormia 91109
}

In their recent paper, Isacks et al., [1968] performed a valuable service by presenting an inclusive view of this actively expanding subject. They reported much new material and contributed new facets to the discussion.

What follows refers to points that seem of special importance, or that fall specifically in the writer's own field. A number of minor matters have been passed over because they could be discussed more competently by others. Probably the most significant questions arise with regard to the tectonics of Japan and of the Alpide belt.

The authors cautiously avoid the two extremes common in discussion of Japan: Treating the tectonic belt as a simple succession of arc structures, and referring it to uniform regional stresses and displacements as if it were simply a block structure. However, there is here no explicitly integrated treatment, but the two points of view are brought in separately, with qualifying remarks.

For short summaries on Japan refer to the present writer's textbook [Richter, 1958], to Miyamura [1962], or to Matuzawa [1964].

The tectonic complexity of Japan is too often obscured in global discussions by mapping on a very small scale. Any general scheme should at least be coherent with the major features, including

1. The fairly typical arc involving eastern Honshu.

2. Its southward continuation along a chain of small islands, with all the typical features but unusually rectilinear.

\footnotetext{
1 Division of Geological Sciences Contribution 1591.
}

Copyright (c) 1969 by the American Geophysical Union.
3. The arc of the Ryukyu Islands and Kyushu, typical except for apparent lack of earthquake foci deeper than the intermediate range.

4. The active zone off the south coasts of Shikoku and Honshu.

5. The zone of deep shocks crossing under Honshu, which most authors refer to features 1 and 2 above.

6. The fracture zone across Honshu belonging to the Mino-Owari (Nobi) earthquake of 1891.

7. The median tectonic line, running E-W across Honshu and Shikoku into Kyushu.

8. The fossa magna, generally cited as the principal internal tectonic boundary of Japan.

Features 1 and 2 present no major difficulties, although one would like an explanation of an apparent great change in the dip of the active surface, since under the Japan Sea the shocks at depths of 350 and $500 \mathrm{~km}$ are much farther from the arc front than the corresponding shocks south of Honshu. To understand feature 3 , as well as the Philippine arcs, we need a clearer picture of the tectonics of the Philippine Sea. The arc features of 3 , particularly as confirmed by dormant volcanoes, clearly extend north through Kyushu and under the structures of the median tectonic line. The median tectonic line (feature 7) has figured in geological literature chiefly as a zone of intense thrusting, which is not hard to fit into regional tectonics. There are recent observations, which, if confirmed, demonstrate recent right-hand strike slips [Kaneko, 1968]. This interpretation is coherent with the displacements on faults with approximately the same trend in the entire region. It would defeat any attempt to explain the median line as a transform fault between the arcs 1 and 3. The expedient used by the 
authors for New Zealand and the Philippine fault cannot be applied, because the two arcs both dip westward. Transform faulting could be postulated with geometric consistency along the Mino-Owari line, with left-lateral displacements, but a southern terminus could hardly be pointed out. The fossa magna may not need to be considered in relation to events of the last $10 \mathrm{~m} . \mathrm{y}$., but enormous lateral shifts have occurred there in the past and must be accounted for if present reasoning is to be extended back in geologic time.

The authors cite the writer's textbook [Richter, 1958] as authority for what is indeed well known and has long been so: 'vertical movements in island arcs are of primary importance.' I do not find this particular wording; if I used it, it was somewhat incautious, since 'importance' is a difficult word to interpret precisely. Immediately following, the authors note the very definite evidence of strike-slip displacements in regions of arc structure, such as Japan. By citing only the Niigata earthquake of 1964, room is left for the impression that this is an individual and perhaps a local occurrence; however, block structures with strikeslip extend over a great part of Honshu, especially near the Japan Sea coast.

I feel that block faulting in the interior of arc structures is not fully considered. By regarding the San Andreas fault, and the Alpine fault of New Zealand as transform faults, the two largest parts of the Pacific belt in which block faulting dominates are accounted for, but, as suggested in connection with the median tectonic line, this leaves difficulties with regard to Japan, not to mention other areas such as Peru and the southwestern Philippines.

It is unsatisfactory to describe the Alpide belt as an area of scattered or diffuse seismicity. There is a sprinkling of epicenters of minor shocks, hardly more notable than in the interiors of many of the active Pacific arcs; especially in Europe these shocks tend to be overemphasized because of relatively complete detection and registration. There is a strong concentration of epicenters, including most of the larger events, along the southern front, which in the Mediterranean region has a very sinuous course. In the eastern Mediterranean there is an interesting occurrence of epicenters outside the arc. The northern front is less easily traced from epicenter data, although it includes the Carpathian arc with its intermediate earthquakes. There is a gap in known seismicity in the north front between $60^{\circ}$ and $67^{\circ} \mathrm{E}$ (from east of Ashkhabad to the area of the Karatag earthquake of 1907).

East of the Pamir, the southern front can readily be traced on seismological and geological maps as far as Burma. The northern front here differs in character: it consists of the northeasttrending Pamir-Baikal belt, readily traceable by epicenters to about $120^{\circ} \mathrm{E}$. Between this front and the southern front, seismicity can hardly be called diffuse; the region is broken into large blocks, separated by mountain structures along which the principal epicenters are aligned.

East Africa is another area for which the authors' reference to diffuse activity is arguable. What appears as a featureless scatter on a smallscale map is actually in clear relation to the two well-known rift zones, apart from a minority of stray points; these points may represent sporadic small shocks such as occur almost everywhere, or some may simply stand for erroneous locations.

The maps illustrating major divisions of the earth's surface are drafted on the familiar but imperfect Mercator projection, with its distortion at the far north. The active zone from Spitzbergen to the mouth of the Lena appears only in fragments on Figure 3, and not at all on Figure 15, which purports to show all epicenters located by the Coast and Geodetic Survey for 7 years and yet cuts off at $70^{\circ} \mathrm{N}$.

In discussing earthquake swarms, the authors note that some are known from localities in which there is no evident connection with volcanism. Distinction is also desirable between swarms of small shocks preceding eruptions and events on a larger scale, both in magnitude and in time, without any eruption. Among these larger-scale events was the swarm near Jan Mayen, August 20-23, 1954. A similar swarm occurred in the Kermadec Islands in March 1965 , but a swarm associated with an eruption had occurred there in 1964. Perhaps the most remarkable occurrence of this kind in late years happened during June 1968, following an explosive eruption on Fernandina, Galapagos Islands. Hundreds of these shocks were recorded at stations in southern California. When the seismologist observes such a large swarm that does not 
fit the normal pattern of foreshock, main shock, and aftershocks, he is justified in supposing that the source is in a volcanic area. As the Kermadec instance shows, an island arc source'may be involved, but it is probably true that the majority of such sequences are associated with oceanic ridges.

In discussing the maxima of seismicity with respect to depth, a special point is made of absence of such maxima near $300 \mathrm{~km}$. The arrangement of the data has tended to minimize the prevalence of earthquakes near $350 \mathrm{~km}$ in that part of the Japanese transverse belt that extends from the south coast of Honshu across the Japan Sea.

It is no criticism of the authors that they do not present a satisfactory explanation for the Spanish deep shock of March 29, 1954. It does not fit easily into any general scheme. It might be referred to the active arc of Italy, with which are associated shocks known at depths of 300 $400 \mathrm{~km}$ under the Tyrrhenian Sea, but even with a depth of $680 \mathrm{~km}$ the Spanish shock is so far west that it would imply an abnormally low dip of the seismic active surface. The authors' suggestion of a completely detached structure within the mantle is as good as any explanation. Since this earthquake apparently represents a rare occurrence, we are fortunate to have it so well observed, thereby shutting off some too facile generalizations. It may be well to assure those not familiar with the observational details that the evidence for epicenter and depth is first class and that the possibility of significant reinterpretation of these data is extremely remote.

The authors are at pains to refute Gutenberg's submarine-slide theory of tsunamis; I doubt if the idea now has many adherents. Local and minor waves undoubtedly originate in this way, but major tsunamis do not.

To the authors' discussion of maximum earthquakes, it should be noted that a longer rupture need not correspondingly increase the instrumental magnitude, which depends rather on the maximum rate of radiation of energy than on the total.
The authors point out that they have used 'strength' in a general sense without attempting closer definition. This usage opens pitfalls that have been avoided here, but the literature of geology includes many instances in which such procedure has led to confusion and to incorrect conclusions. Refer to Hubbert [1937].

'Are the focal mechanisms of earthquakes at depth really as much like those in near-surface brittle materials as they seem?' Possibly they are not so much so as they are here taken to be. Focal-mechanism analysis from seismograms is less definite for most of the large shallow earthquakes than it is for deep-focus earthquakes. Instances are accumulating that indicate that large shallow shocks commonly consist of a complex series of events, of which the earliest often is not the largest on the seismograms; the sense of first deflection then is difficult to read, and focal determinations from distant stations may refer to the later event rather than the initial one. An example is the great Alaskan earthquake of 1964 [Wyss and Brune, 1967]; another was the large Aleutian event of February 7,1965 , as was promptly pointed out in the bulletins for Uppsala, Strasbourg, Pasadena, and other stations.

\section{REFERENCES}

Hubbert, M. K., Theory of scale models as applied to the study of geologic structures, Bull. Geol. Soc. Am., 48, 1459, 1937.

Isacks, B., J. Oliver, and L. R. Sykes, Seismology and the new global tectonics, J. Geophys. Res., $73,5855,1968$.

Kaneko, S., Is the median tectonic line active? (in Japanese), Kagaku Asahi, Tokyo, 89, July 1968.

Matuzawa, T., Study of Earthquakes, 213 pp., Uno Shoten, Tokyo, 1964.

Miyamura, S., Types of crustal movements accompanied with earthquakes, Deut. Akad. Wisse. Berlin, Intern. Symp. Erdkrustenbewegungen, no. 1, 235, 1962.

Richter, C. F., Elementary Seismology, 768 pp., W. H. Freeman and Co., San Francisco, 1958. Wyss, Max, and James N. Brune, The Alaska earthquake of 28 March 1964: A complex multiple rupture, Bull. Seismol. Soc. Am., 57, 1017, October 1967.

(Received November 25, 1968.) 